\title{
REMOÇÃO de SUBSTÂNCIAS HÚMICAS POR MEIO DA OXIDAÇÃO COM OZÔNIO E PERÓXIDO DE HIDROGÊNIO E FIME
}

\author{
REMOVAL OF HUMIC SUBSTANCES BY MEANS OF OXIDATION WITH OZONE \\ AND HYDROGEN PEROXIDE AND FIME
}

\begin{abstract}
EDSON PEREIRA TANGERINo
Engenheiro Civil. Doutor em Hidráulica e Saneamento pela Escola de Engenharia de São Carlos. Professor do Departamento de Engenharia Civil da Faculdade de Engenharia de Ilha Solteira - UNESP

\section{LUIZ DI BERNARDO}

Engenheiro Civil. Doutor em Engenharia Civil da Escola de Engenharia de São Carlos - USP.

Professor Titular da Escola de Engenharia de São Carlos - USP
\end{abstract}

Recebido: 12/11/04 Aceito: 13/09/05

\section{RESUMO}

A filtração em múltiplas etapas (FiME) se apresenta como uma alternativa para realizar o tratamento de água de comunidades de pequeno porte, entretanto, a eficiência quanto à remoção de cor verdadeira associada ao carbono orgânico dissolvido (COD) ou às substâncias húmicas, tem sido questionada ou relatada como baixa. A presente pesquisa avaliou a remoção de substâncias húmicas na FiME com pré-oxidação, com ozônio e peróxido de hidrogênio, utilizando para essa avaliação parâmetros indiretos como cor verdadeira, absorvância UV (254 nm) e COD. Foram realizados cinco ensaios, utilizando quatro filtros lentos, sendo dois com camada de carvão ativado granular (CAG). Foram ensaiadas várias alternativas de pré-oxidação com ozônio e peróxido de hidrogênio. Foram obtidos bons resultados, tendo como principal conclusão que os filtros lentos com CAG, precedidos de oxidação com ozônio e depois peróxido de hidrogênio, apresentaram remoção média de cor verdadeira de 64\%, mas que o peróxido de hidrogênio afeta o desenvolvimento da camada biológica, interferindo no desenvolvimento da perda de carga, na remoção de turbidez, na remoção de coliformes e na remoção de substâncias húmicas.

PALAVRAS-CHAVE: Substâncias húmicas, filtração lenta, oxidação, ozônio, peróxido de hidrogênio.

\begin{abstract}
The multistage filtration (FiME) is an alternative to accomplish water treatment for small communities, however, as for removal of true color associated to dissolved organic carbon (DOC) or humic substances, it have been questioned or reported as low efficiency. The present research evaluated the removal of humic substances in the FiME using ozone and hydrogen peroxide as a pre-oxidation, using for this indirect parameters how true color, UV absorbance (254nm) and DOC. Five experiments were conducted using four slow filters, from this two were composed the intermediate layer of granulate activated carbon (GAC). The assays were conducted with preoxidation alternatives using ozone and hydrogen peroxide in several applications forms. It was obtained good result, as main conclusion were the slow filters with $G A C$, preceded of oxidation with ozone and hydrogen peroxide in appropriate dosage, presented medium removal of true color of $64 \%$, but that the hydrogen peroxide interfering in the development of the biological layer, in the increase of the head loss, in the turbidity removal, in the coliforms removal and in the humic substances removal.
\end{abstract}

KEYWORDS: Humic substances, slow sand filtration. oxidation, ozone, hydrogen peroxide.

\begin{tabular}{|c|c|c|}
\hline $\begin{array}{l}\text { INTRODUÇÃO } \\
\text { A desinfecção de águas para abaste- } \\
\text { cimento tem ajudado a erradicar doenças } \\
\text { veiculadas pela água, sendo o cloro o agen- } \\
\text { te oxidante mais usado, cuja principal } \\
\text { função é a inativação de organismos } \\
\text { patogênicos causadores dessas doenças. } \\
\text { Nos últimos anos, sem tirar os grandes } \\
\text { méritos e atributos do cloro, alguns } \\
\text { subprodutos tóxicos, foram descobertos } \\
\text { nas águas de abastecimento, originados } \\
\text { da ação do cloro sobre compostos orgâni- } \\
\text { cos, tais como os ácidos húmicos e fúlvicos. }\end{array}$ & $\begin{array}{l}\text { A presença de matéria orgânica na- } \\
\text { tural (MON) em águas de abastecimen- } \\
\text { to tem recebido a atenção de diversos } \\
\text { pesquisadores desde a década de } 70 \text {. A } \\
\text { presença elevada de MON em mananci- } \\
\text { ais para abastecimento público apresenta } \\
\text { aspectos negativos, dentre os quais se po- } \\
\text { dem citar: confere cor elevada à água bruta, } \\
\text { dependendo dos compostos orgânicos } \\
\text { presentes, pode causar odor e sabor, pode } \\
\text { gerar subprodutos ao ser exposta a agen- } \\
\text { tes oxidantes e desinfetantes, como, clo- } \\
\text { ro, dióxido de cloro, ozônio, cloraminas, } \\
\text { radiação ultravioleta, etc., que podem ser }\end{array}$ & $\begin{array}{l}\text { tóxicos, cancerígenos, mutagênicos ou } \\
\text { teratogênicos e que em elevadas concen- } \\
\text { traçôes e longos períodos de exposição } \\
\text { podem causar danos à saúde pública. A } \\
\text { MON presente em meio aquoso é forma- } \\
\text { da por processos biológicos naturais de } \\
\text { degradação de matéria vegetal e sua } \\
\text { interação com argila e demais constituin- } \\
\text { tes do solo, como também pela atividade } \\
\text { biológica de algas e outros microrganismos. } \\
\text { A filtração lenta em leito de areia é } \\
\text { um método de tratamento apropriado } \\
\text { para produzir água potável. É simples, } \\
\text { de baixo custo e de tecnologia segura, que }\end{array}$ \\
\hline
\end{tabular}


pode ser usada quando a água superficial está facilmente disponível e com qualidade. A filtração lenta em areia é uma tecnologia de tratamento de água eficiente, que pode produzir efluentes com baixa turbidez, baixa quantidade de impurezas dissolvidas, de bactérias, de vírus entéricos e de protozoários (Galvis et al, 1997). Em filtros lentos de areia o tratamento da água éalcançada através da combinação de processos físico-químicos e biológicos. Segundo Di Bernardo (1993), o biofilme que se desenvolve sobre a camada de areia, o "schmutzdecke", é uma comunidade heterogênea que consiste em bactérias, algas, protozoários e invertebrados e seus produtos extracelulares, etc., além de precipitados de ferro e manganês, quando esses metais se encontram no afluente. A atividade de microrganismos no "schmutzdecke" é um dos fatores chaves para se obter água de boa qualidade, sendo mais pronunciada no topo do meio filtrante, mas se estendendo até cerca de $40 \mathrm{~cm}$ de profundidade. Contudo, para que a filtração lenta apresente resultados satisfatórios, é necessário que as características do afluente estejam limitadas a valores relativamente baixos de turbidez, cor verdadeira, sólidos suspensos, coliformes, entre outros.

Com o aumento da atividade humana, interferindo nas condiçôes de proteção dos mananciais, surgiu a necessidade de se efetuar o pré-tratamento da água a ser utilizada pela filtração lenta. O processo de FiME se apresenta como a melhor alternativa para essa finalidade, sendo uma combinação de tratamentos em filtros de pedregulho e filtros lentos de areia, mantendo as vantagens de exigir baixos custos de implantação, manutenção e operação. Entretanto, segundo Cleasby et al (1984), Ellis (1985) e Collins (1991) apud Galvis et al (1997), a sua eficiência, quanto à remoção de cor verdadeira associada ao carbono orgânico dissolvido ou a substâncias húmicas, tem sido questionada ou relatada como baixa (25 a 30\%). Várias pesquisas vêm sendo realizadas para melhorar a eficiência de remoção de cor, como a utilização de carvão ativado em camada intermediária do filtro lento ou com a aplicação de ozônio na água bruta.

Segundo Greaves et al (1988), os estudos desenvolvidos com filtração lenta, precedida de pré-oxidação com ozônio, demonstraram que essa tecnologia constitui uma boa opção para a remoção de cor. O ozônio oxida os compostos de peso molecular alto, transformando-os em composto de menor peso molecular, que são mais facilmente biodegradáveis. Segundo Rook (1974) apud Yordanov et al (1996), a ozonização seguida de filtração lenta pode remover grande parte dos materiais orgânicos assimiláveis, prevenindo o recrescimento de microrganismos no sistema de distribuição e também reduzindo os produtos potencialmente formadores de trialometanos.

Vários pesquisadores, segundo Langlais et al (1999), estudaram o uso do carvão ativado na filtração lenta. Todos confirmam que o carvão proporciona aumento de remoção de cor, sabor e odor no filtro lento, reduzindo também os subprodutos da desinfecção. A camada de carvão ativado granular deve estar sob uma camada de areia, que protege o carvão de uma carga excessiva de matéria orgânica particulada; a camada superior de areia funciona como filtro lento natural e o carvão como adsorvedor, segundo Coelho (2002).

Os processos avançados de oxidação geram radicais $\mathrm{OH}^{-}$, que são altamente reativos e são capazes de oxidar várias combinações de compostos na água. Nesses processos ocorre uma aceleração da taxa de decomposição de ozônio, a concentração de radicais $\mathrm{OH}^{-}$é elevada, o que provoca aumentos na taxa de oxidação. Este procedimento aumenta a contribuição de oxidação pelos radicais $\mathrm{OH}^{-}$em relação à oxidação direta pelo ozônio. Vários métodos podem ser usados para aumentar a decomposição do ozônio, um dos mais comuns envolve a adição de peróxido de hidrogênio, antes ou depois do ozônio, sendo esse processo conhecido como peroxônio. Peroxônio é um dos germicidas mais potentes e efetivos usados em tratamento de água. É ligeiramente mais efetivo que o ozônio contra bactérias, vírus e cistos de protozoários.

A presente pesquisa teve a finalidade de avaliar a influência da pré-oxidação com ozônio e peróxido de hidrogênio no desempenho da filtração lenta, com ou sem camada intermediária de carvão ativado, com água bruta previamente condicionada em pré-filtros de pedregulho, quanto à remoção de substâncias húmicas, analisada através de parâmetros substitutivos como cor verdadeira, carbono orgânico dissolvido e absorvância.

\section{REVISÃO BIBLIOGRÁFICA}

\section{Substâncias húmicas}

As substâncias húmicas (SH) são resultantes de reaçôes químicas, fotoquí- micas e microbiológicas que ocorrem durante a degradação da matéria vegetal. As SH têm sido usadas para representar os componentes orgânicos naturais presentes na água, em virtude de sua origem natural e de sua alta concentração na água. As $\mathrm{SH}$ apresentam características muito variáveis, mas em geral são compostas principalmente de carbono orgânico húmico, ácidos húmicos, ácidos fúlvicos em porcentagens variáveis, dependendo do local de origem.

A medida de remoção de substâncias húmicas é difícil de ser efetuada. É normalmente feita através de parâmetros substitutivos como cor verdadeira, absorvância $254 \mathrm{~nm}$, COD, etc. A remoção de substâncias húmicas na filtração lenta é tida como baixa. Grahan (1999) relata remoçóes de $18 \%$ de cor, $42 \%$ de absorvância e de 9 a 15\% de COD, conforme mostrado na Tabela 1 .

Alguns autores relatam que obtiveram remoções em torno de $86 \%$ de cor verdadeira, valor esse muito difícil de ocorrer, em se tratando de filtração lenta.

Alguns pesquisadores e projetistas vêm utilizando o ozônio como préoxidante para aumentar a remoção da cor. O ozônio vem sendo utilizado como préoxidante na filtração lenta, pois tem a vantagem de praticamente não deixar efeito residual, quando aplicado em dosagens adequadas, e aumenta a biodegradabilidade do carbono orgânico.

Segundo Graham (1999), podem ser obtidas remoções de cor desde valores de $52 \%$ a $82 \%$, nos processos oxidação/filtração lenta na faixa. Essa variação de valores encontra uma explicação na grande variação das características das substâncias húmicas, em função de seu local de origem.

Nos processos avançados de oxidação tem sido investigada a relação entre as dosagens de peróxido de hidrogênio e de ozônio. Pesquisas realizadas por Freeze et al (1999) indicaram que a melhor relação está entre 0,3 e 0,5 , como pode ser observado pelas curvas de remoção de absorvância UV e de formação de carbono orgânico dissolvido biodegradável (CODB) na Figura 1.

A absorvância diminuiu até a relação 0,3 e permaneceu constante com o aumento da relação peróxido/ozônio. Os valores de formação de $\mathrm{CODB}$ atingiram o máximo com a relação igual a 0,5 . Acima dessa relação ocorre aumento do residual de peróxido e o processo de oxidação passa a ser seletivo através das moléculas de ozônio e não pelos radicais $\mathrm{OH}^{-}$que tem ação mais rápida e potente. 
Quanto ao ponto de aplicação do peróxido de hidrogênio em relação ao ozônio, em geral o que se encontra na literatura é que essa aplicação é efetuada antes do ozônio, mas estudos realizados por Duquet e mostrados por Langlais et al (1999), indicaram que aplicando o peróxido de hidrogênio após o ozônio obtêm-se maior remoção de absorvância, como pode ser observado na Tabela 2 , onde a aplicação do peróxido de hidrogênio junto com o ozônio removeu 58\% da absorvância, enquanto a aplicação efetuada depois de 4 a 8 minutos de iniciada a ozonização removeu $75 \%$ da absorvância.

\section{MATERIAIS E MÉTODOS}

O presente trabalho constou de investigação experimental na instalação de filtração em múltiplas etapas, que se encontrava montada junto à Estação de Tratamento de Água da cidade de São Carlos, construída pelo Departamento de Hidráulica e Saneamento da EESC-USP. Foram realizadas pequenas alteraçôes na instalação, para possibilitar variações de dosagens de substâncias húmicas, ozônio e peróxido de hidrogênio.

A água bruta era derivada da adutora do Ribeirão do Feijão para um reservatório, sendo em seguida recalcada para uma câmara localizada no ponto mais alto da instalação, com dispositivo de medição e de controle de vazão. Por gravidade essa água passava para o pré-filtro dinâmico (PFD). Desse PFD a água passava para uma câmara com vertedor e controle de vazão; através de dispositivo de manobra uma parte da água era encaminhada, por gravidade, ao pré-filtro de escoamento ascendente (PFVA). Na saída do PFVA ficava o ponto de aplicação, de substâncias húmicas. Desse ponto a água era encaminhada, por gravidade, para a câmara de mistura e de sucção do conjunto elevatório que recalcava para uma caixa de nível constante. Na tubulação de saída dessa caixa de nível constante foi instalado um dispositivo construído com tubulações de PVC, em forma de chicanas, para dosagem e mistura do peróxido de hidrogênio. Desse dispositivo derivavam duas tubulações em cujas extremidades foram instalados cotovelos com "plugs". Esses "plugs", com orifícios perfurados, foram instalados de tal forma que suas alturas pudessem ser reguladas conforme a vazão desejada. Uma dessas tubulações alimentava a coluna de ozonização, que por sua vez alimentava

Tabela I - Remoções médias de parâmetros indicativos de SH

\begin{tabular}{|c|c|c|}
\hline Parâmetro & Remoção média (\%) & Fonte \\
\hline \multirow[t]{3}{*}{ Cor verdadeira } & 33 & Coelho (2002) \\
\hline & 86 a 89 & Galvis et al (1999 \\
\hline & 18 & Grahan (1999) \\
\hline Absorvância & 42 & Grahan (1999) \\
\hline Ccarbono orgânico dissolvido & 9 a 15 & Grahan (1999) \\
\hline
\end{tabular}

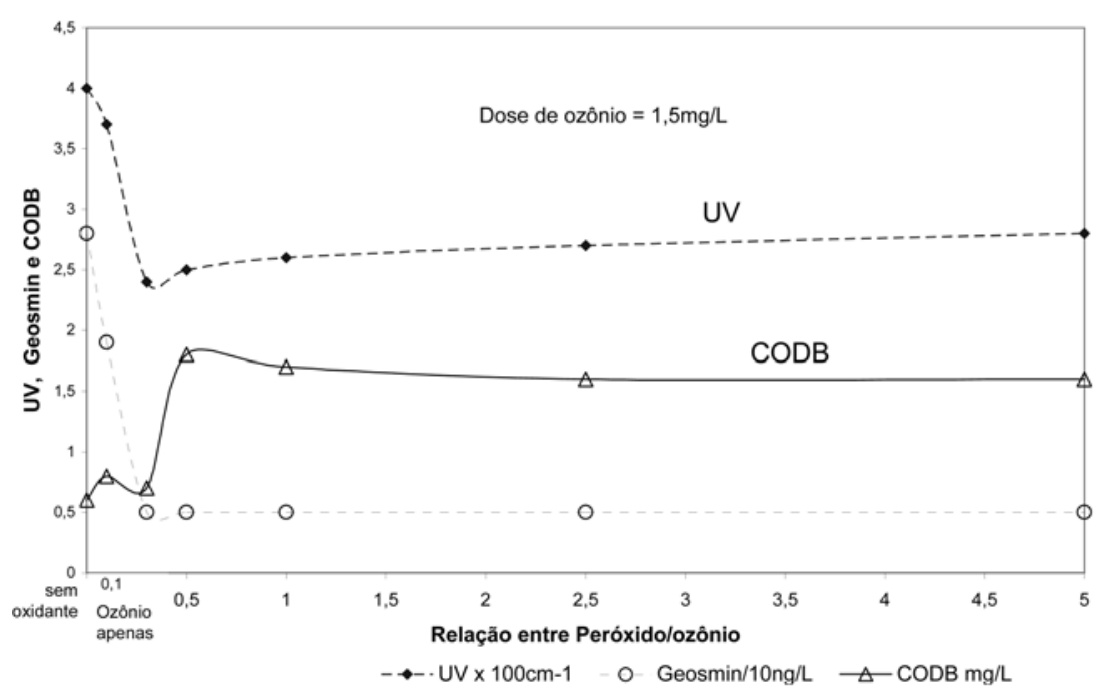

Figura I - Efeito da variação da relação $\mathrm{H}_{2} \mathrm{O}_{2} / \mathrm{O}_{3}$ sobre valores de absorvância UV, Geosmin e CODB na água tratada (adaptado de Freese et al (1999))

Tabela 2 - Influência do ponto de aplicação do peróxido de hidrogênio em relação ao ozônio na remoção de absorvância (adaptada de Langlais et al ( 991 ))

\begin{tabular}{ccccc}
\hline Tipo de água & $\begin{array}{c}\text { Absorvância } \\
\text { inicial 254 } \\
\left(\mathrm{cm}^{-1}\right)\end{array}$ & $\begin{array}{c}\text { Remoção percentual de absorvância } \\
\mathrm{O}_{3}+\mathrm{H}_{2} \mathrm{O}_{2} \\
(\mathrm{t}=0)\end{array}$ & $\begin{array}{c}\mathrm{O}_{3}+\mathrm{H}_{2} \mathrm{O}_{2} \\
(\mathrm{t}=4 \mathrm{a} 8 \mathrm{~min})\end{array}$ \\
\hline $\begin{array}{c}\text { Água tratada do } \\
\text { Rio Sena }\end{array}$ & 3,6 & 28 & 58 & 75 \\
Água subterrânea & 2,4 & 36 & 39 & 67 \\
\hline
\end{tabular}

os filtros lentos, sendo um com camada intermediária de carvão ativado (FLC1) e outro com leito de areia (FLA1). A outra tubulação serviu como linha alternativa de alimentação dos outros dois filtros, quais sejam FLC2 e FLA2. A Tabela 3 apresenta as características dos meios filtrantes dos filtros lentos da instalação piloto.

\section{Preparo das substâncias húmicas}

As substâncias húmicas foram obtidas a partir de turfas coletadas numa re- gião de várzea próxima ao rio Mogi Guaçu. Para cada 50 litros de água destilada foi utilizado aproximadamente $1 \mathrm{~kg}$ de turfa e um quilo de hidróxido de sódio $(\mathrm{NaOH})$, essa solução sofria agitação durante $18 \mathrm{~h}$ e depois mantida em repouso por $48 \mathrm{~h}$. O sobrenadante foi embalado em papel celofane e colocado em formas de plástico em solução ácida (com ácido clorídrico $\mathrm{HCl}$ ) com $\mathrm{pH}=2$ onde ocorria diálise por $48 \mathrm{~h}$, com troca da solução ácida três vezes ao dia. Após essa fase ocorria nova diálise em água não clorada até que fosse obtida reação negativa a cloreto, utilizando o nitrato de prata como teste. 
Tabela 3 - Características granulométricas e espessura da camada suporte e meio filtrante de cada filtro lento

\begin{tabular}{|c|c|c|c|}
\hline \multicolumn{2}{|c|}{ Unidades } & $\begin{array}{l}\text { Tamanho do material } \\
(\mathrm{mm})\end{array}$ & $\begin{array}{c}\text { Espessura da camada } \\
(\mathrm{m})\end{array}$ \\
\hline \multirow{5}{*}{\multicolumn{2}{|c|}{ Camada suporte }} & 31,4 a 50,0 & 0,30 \\
\hline & & 15,9 a 25,4 & 0,15 \\
\hline & & 7,9 a 12,7 & 0,10 \\
\hline & & 3,2 a 6,4 & 0,10 \\
\hline & & 1,41 a 2,4 & 0,10 \\
\hline \multirow[t]{4}{*}{ Meio filtrante } & FLC1 & 0,08 a 1,0 (areia) & 0,10 \\
\hline & e & 0,30 a 0,84 (CAG) & 0,30 \\
\hline & FLC2 & 0,08 a 1,0 (areia) & 0,30 \\
\hline & $\begin{array}{c}\text { FLA1 } \\
\text { e } \\
\text { FLA2 }\end{array}$ & 0,08 a 1,0 (areia) & 0,80 \\
\hline
\end{tabular}

Foram preparados 1000 litros desse material concentrado, o qual apresentava cor verdadeira em torno $40000 \mathrm{uH}$. Esse material foi homogeneizado em um tanque e depois armazenado em bombonas de plástico de 200 litros.

\section{Ensaios realizados}

Foram realizados cinco ensaios. Nos ensaios 1 e 2 foi utilizada água natural pré-filtrada (NPF), enquanto que nos ensaios 3 e 4 foi utilizada água natural pré-filtrada com aplicação de substâncias húmicas $(\mathrm{NPF} / \mathrm{SH})$. No quinto ensaio os filtros FLC1 e FLA1 operaram com água natural pré-filtrada, enquanto que os filtros FLC2 e FLA2 receberam água com aplicação de substâncias húmicas. Para que a gama de opções de oxidação fosse realizada, foi necessário efetuar adaptaçôes na instalação antes do início de cada ensaio. Essas modificações constaram basicamente de mudanças nos pontos de aplicação do peróxido de hidrogênio e das substâncias húmicas. Ao final de cada carreira foram realizadas as operaçôes de raspagens das camadas biológicas dos filtros.

A programação dos ensaios foi feita visando cobrir as várias possibilidades de pré-oxidação ou não, nos filtros de areia ou com carvão, com ou sem aplicação de substâncias húmicas. A Tabela 4 mostra a programação dos ensaios realizados em função da água utilizada, dos oxidantes e da aplicação das substâncias húmicas. A Figura 2 apresenta um esquema típico da instalação, sendo que esse esquema correspondeu às condiçỗes da realização do segundo ensaio.

Foram efetuadas determinaçôes diárias de cor verdadeira e aparente, turbidez, $\mathrm{pH}$, temperatura e perda de carga. As análises de absorvância e carbono orgânico dissolvido foram efetuadas três vezes por semana. $\mathrm{O}$ controle da dosagem de oxidantes foi efetuado diariamente e os demais parâmetros uma vez por semana.

\section{RESULTADOS E DISCUSSÃO}

A avaliação da remoção das substâncias húmicas foi efetuada através de parâmetros substitutivos como cor verdadeira, absorvância, carbono orgânico dissolvido e oxigênio consumido.

\section{Remoção de cor verdadeira}

A remoção de cor verdadeira foi o parâmetro mais analisado. Inicialmente foi constatado que quando ocorria variação da cor afluente à instalação, ocorria uma variação correspondente na cor efluente de cada componente da instalação.

Tabela 4 - Resumo dos ensaios

\begin{tabular}{|c|c|c|c|c|c|c|c|c|c|c|c|c|c|}
\hline \multirow[t]{3}{*}{ Ensaio } & \multirow{3}{*}{$\begin{array}{c}\text { Duração } \\
\text { do } \\
\text { Ensaio } \\
\text { (d) }\end{array}$} & \multicolumn{12}{|c|}{ Condiçôes de operações dos filtros lentos } \\
\hline & & \multicolumn{3}{|c|}{ FLC1 } & \multicolumn{3}{|c|}{ FLA1 } & \multicolumn{3}{|c|}{ FLC2 } & \multicolumn{3}{|c|}{ FLA2 } \\
\hline & & $\begin{array}{l}\text { Taxa } \\
(\mathrm{m} / \mathrm{d})\end{array}$ & $\begin{array}{l}\text { Cor } \\
(\mathrm{uH})\end{array}$ & Pré-oxid. & $\begin{array}{l}\text { Taxa } \\
(\mathrm{m} / \mathrm{d})\end{array}$ & $\begin{array}{l}\text { Cor } \\
(\mathrm{uH})\end{array}$ & Pré-oxid. & $\begin{array}{l}\text { Taxa } \\
(\mathrm{m} / \mathrm{d})\end{array}$ & $\begin{array}{l}\text { Cor } \\
(\mathrm{uH})\end{array}$ & Pré-oxid. & $\begin{array}{l}\text { Taxa } \\
(\mathrm{m} / \mathrm{d})\end{array}$ & $\begin{array}{l}\text { Cor } \\
\text { (uH) }\end{array}$ & Pré-oxid. \\
\hline $1^{\mathrm{a}}$ & 73 & 4 & NPF & $\mathrm{O}_{3}$ & 4 & NPF & $\mathrm{O}_{3}$ & 4 & NPF & - & - & - & - \\
\hline $2^{\mathrm{a}}$ & 62 & 4 & NPF & $\mathrm{H}_{2} \mathrm{O}_{2}$ e $\mathrm{O}_{3}$ & 4 & NPF & $\mathrm{H}_{2} \mathrm{O}_{2}$ e $\mathrm{O}_{3}$ & 4 & NPF & $\mathrm{H}_{2} \mathrm{O}_{2}$ & 4 & NPF & $\mathrm{H}_{2} \mathrm{O}_{2}$ \\
\hline $3^{a}$ & 94 & 4 & $\mathrm{NPF} / \mathrm{SH}$ & $\mathrm{H}_{2} \mathrm{O}_{2}$ e $\mathrm{O}_{3}$ & 4 & $\mathrm{NPF} / \mathrm{SH}$ & $\mathrm{H}_{2} \mathrm{O}_{2}$ e $\mathrm{O}_{3}$ & 4 & $\mathrm{NPF} / \mathrm{SH}$ & $\mathrm{H}_{2} \mathrm{O}_{2}$ & 4 & $\mathrm{NPF} / \mathrm{SH}$ & $\mathrm{H}_{2} \mathrm{O}_{2}$ \\
\hline $4^{\mathrm{a}}$ & 65 & 3 & NPF/SH & $\mathrm{O}_{3}$ & 3 & NPF/SH & $\mathrm{O}_{3}$ & 3 & NPF/SH & $\mathrm{O}_{3} \mathrm{e}_{2} \mathrm{O}_{2}$ & 3 & NPF/SH & $\mathrm{O}_{3} \mathrm{e}_{2} \mathrm{O}_{2}$ \\
\hline $5^{a}$ & 90 & 3 & NPF & $\mathrm{O}_{3} \mathrm{e}_{2} \mathrm{O}_{2}$ & 3 & $\mathrm{NPF} / \mathrm{SH}$ & $\mathrm{O}_{3} \mathrm{e}_{2} \mathrm{O}_{2}$ & 3 & $\mathrm{NPF} / \mathrm{SH}$ & - & 3 & $\mathrm{NPF} / \mathrm{SH}$ & - \\
\hline
\end{tabular}

Legenda:

NPF Água natural pré-filtrada (sem substâncias húmicas)

NPF/SH Água natural pré-filtrada com adição de substâncias húmicas (cor. verd. e 50 a $70 \mathrm{uH}$ )

$\mathrm{O}_{2} \quad$ Ozônio

$\mathrm{H}_{2} \mathrm{O}_{2} \quad$ Peróxido de hidrogênio

PFD Pré-filtro dinâmico

PFVA Pré-filtro de escoamento vertical ascendente

FLC1 Filtro lento 1(com areia e carvão ativado)

FLA1 Filtro lento 2 (com areia)

FLC2 Filtro lento 3 (com areia e carvão ativado)

FLA2 Filtro lento 4 (com areia) 


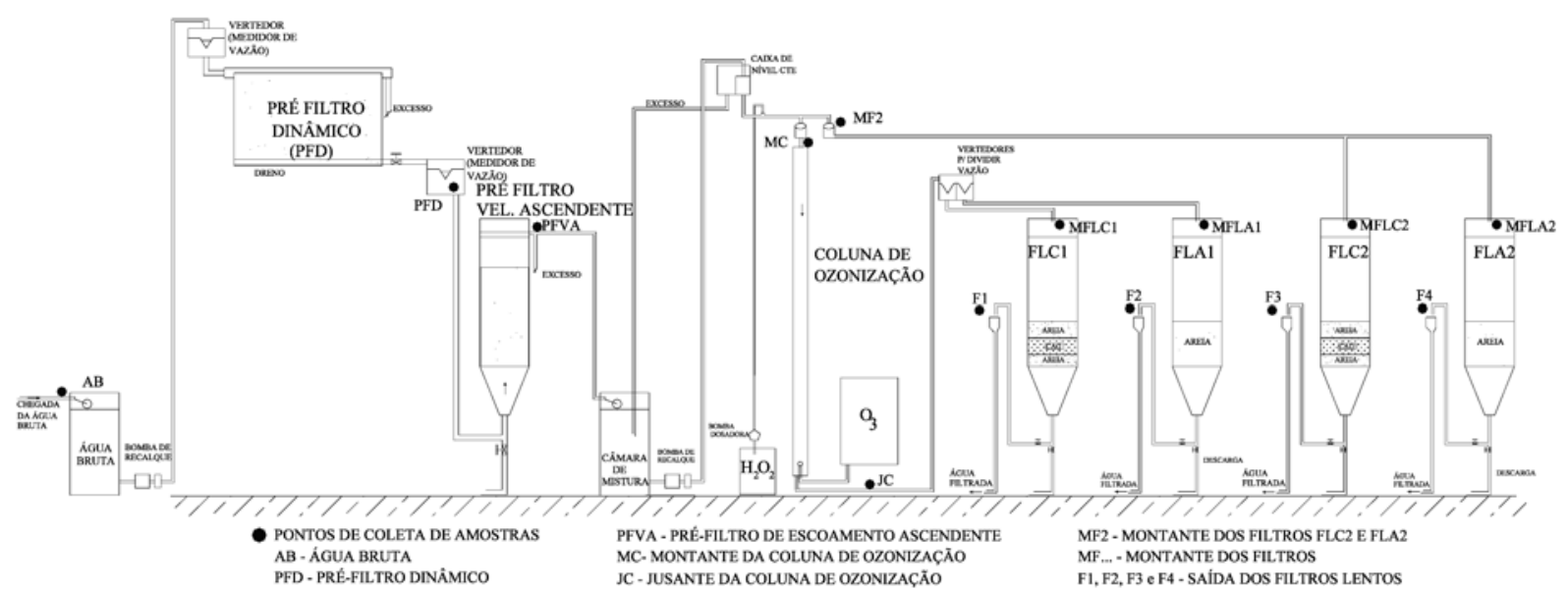

Figura - 2 - Esquema da instalação no segundo ensaio

Na Figura 3, obtida com os dados do quarto ensaio, pode ser notada a melhor eficiência dos filtros com camada intermediária de carvão ativado em relação aos filtros de areia. Nesse caso a cor afluente aos filtros era mantida na faixa de 50 a $70 \mathrm{uH}$, os efluentes dos filtros apresentavam cor na faixa de 20 a $30 \mathrm{uH}$.

A vantagem dos filtros com camada intermediária de carvão ativado granular, quanto à remoção de cor verdadeira, também pode ser observada na Figura 4, que mostra os resultados de remoção de cor no quinto ensaio, onde os filtros com carvão apresentaram remoçóes em torno de $60 \%$, enquanto que os filtros com areia apresentaram remoçôes em torno 50\%.

A remoção média de cor verdadeira no processo de oxidação por ozônio foi de $30 \%$, enquanto o peróxido de hidrogênio, nas dosagens aplicadas, removeu em torno de $1 \%$. No quinto ensaio os filtros FLC1 e FLA1 receberam água préoxidada com ozônio e depois peróxido. Pode ser notado na Figura 5 que a relação cor afluente e efluente dos filtros manteve-se praticamente constante, independentemente da dosagem aplicada de peróxido de hidrogênio. O FLC1 manteve uma remoção em torno de $40 \%$ e o FLA1 em torno de 10 a $15 \%$.

Quando da revisão bibliográfica surgiu a dúvida sobre o ponto de aplicação do peróxido de hidrogênio em relação ao ozônio. Pelos resultados obtidos quanto à remoção de cor verdadeira não se pode afirmar com precisão qual situação é melhor, mas os filtros que receberam água com pré-oxidação com ozônio depois peróxido apresentaram uma ligeira vantagem em alguns ensaios, ou pelo menos apresentaram remoçóes mais cons-

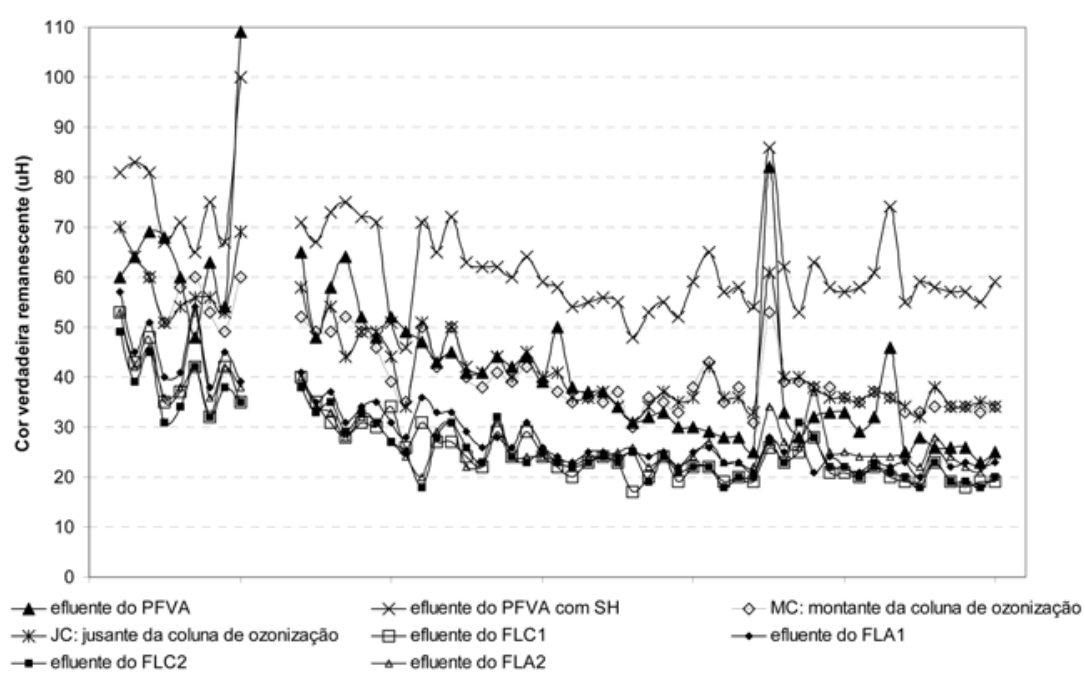

Figura 3 - Variação da cor verdadeira remanescente de cada unidade da instalação ao longo do tempo de operação no ensaio 4. (SH = ponto de coleta após aplicação das substâncias húmicas, $\mathrm{MC}$ e JC = pontos de coleta à montante e à jusante das colunas de ozonização)

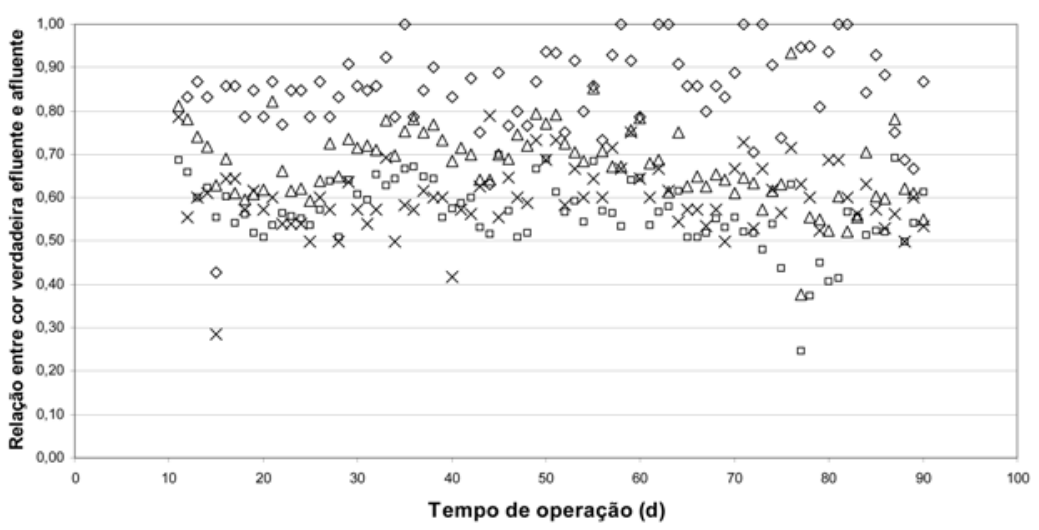

$\times$ Remoção de cor verdadeira no FLC1 recebendo água sem SH $\diamond$ Remoçăo de cor verdaeira no FLA1 recebendo água sem SH - Remoçăo de cor verdadeira no FLC2 recebendo água com SH $\triangle$ Remoção de cor verdadeira no FLA2 recebendo água com SH

Figura 4 - Relação entre valores de cor verdadeira efluente e afluente de cada filtro ao longo do tempo, no quinto ensaio 
tantes ao longo do tempo. Na Figura 6 estão lançados em separado os dados de remoção de cor verdadeira no filtro FLC1, utilizando água pré-oxidada com ozônio mais peróxido de hidrogênio e peróxido mais ozônio. Pode-se observar que a aplicação do peróxido de hidrogênio após a ozonização levou a resultados de remoção de cor verdadeira ligeiramente melhores nos filtros lentos.

A Figura 7 permite também analisar as remoções percentuais de cor em função da pré-oxidação empregada, nesse caso no FLA2, nota-se certa vantagem da aplicação do peróxido após a ozoni-zação. A remoção média ocorrida no processo oxidação/filtração lenta girou em torno de $64 \%$.

\section{Interferência do residual de peróxido de hidrogênio}

Apesar da aparente vantagem do peroxônio de hidrogênio, existe a preocupação com o residual do peróxido no afluente aos filtros lentos. O residual de peróxido de hidrogênio interfere na camada biológica que se forma na camada superior do filtro lento, sendo essa camada a principal responsável pela formação da perda de carga. No segundo ensaio esse fato ficou bem visível, a perda de carga na camada superior do FLA1 estava em $60 \mathrm{~cm}$ antes da aplicação do peróxido de hidrogênio, mas com a aplicação de uma dosagem de $0,7 \mathrm{mg} / \mathrm{L}$ essa perda de carga diminuiu para $10 \mathrm{~cm}$, como pode ser observado através das leituras piezométricas no FLA1 no segundo ensaio, mostrado na Figura 8.

\section{Interferência do residual de peróxido na remoção de turbidez}

Ocorreu interferência na remoção de turbidez de forma negativa, como pode ser observado pelo desempenho do filtro FLA1 no segundo ensaio.

A remoção de turbidez caiu de $60 \%$ para menos de $30 \%$, como mostrado na Figura 9. Foi observado também ao longo dos ensaios que a pré-oxidação não aumentou a remoção de turbidez.

\section{Influência do peróxido de hidrogênio na remoção de cor}

A aplicação do peróxido de hidrogênio afetava também a remoção de cor verdadeira, pois o mesmo apresentava residual que interferia no desenvolvimento da

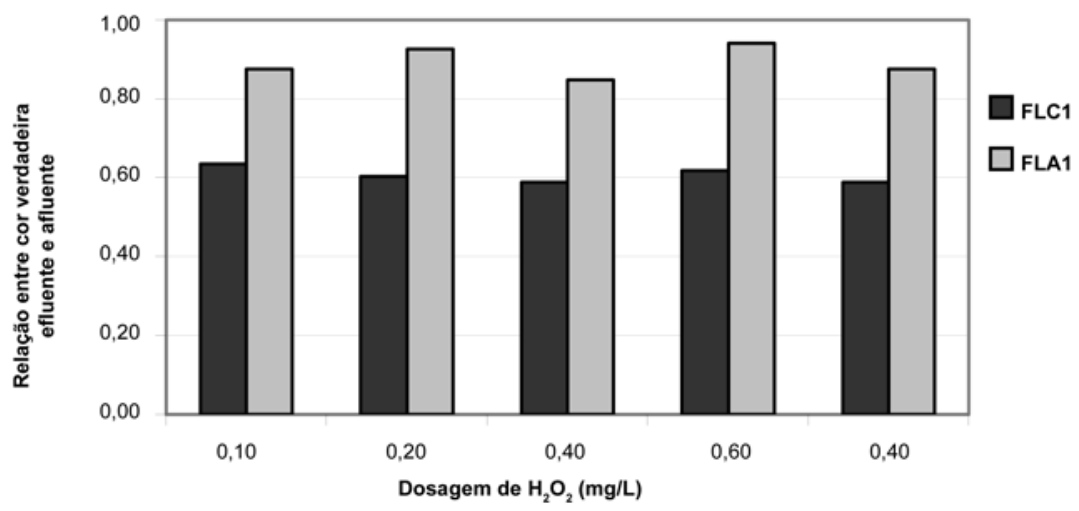

Figura 5 - Relações entre cor verdadeira efluente e afluente nos filtros FLCI e FLAI em função da dosagem de peróxido de hidrogênio

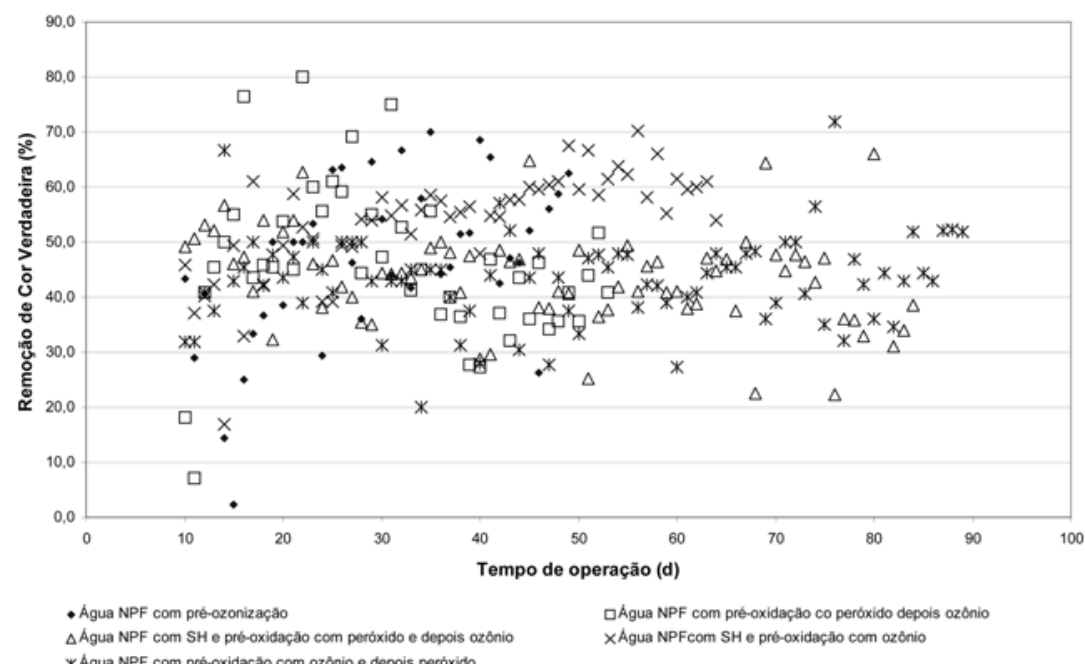

Figura 6 - Comparação dos resultados de remoção de cor pelo filtro FLCI, quando recebia água pré-oxidada com ozônio/peróxido e com peróxido/ozônio

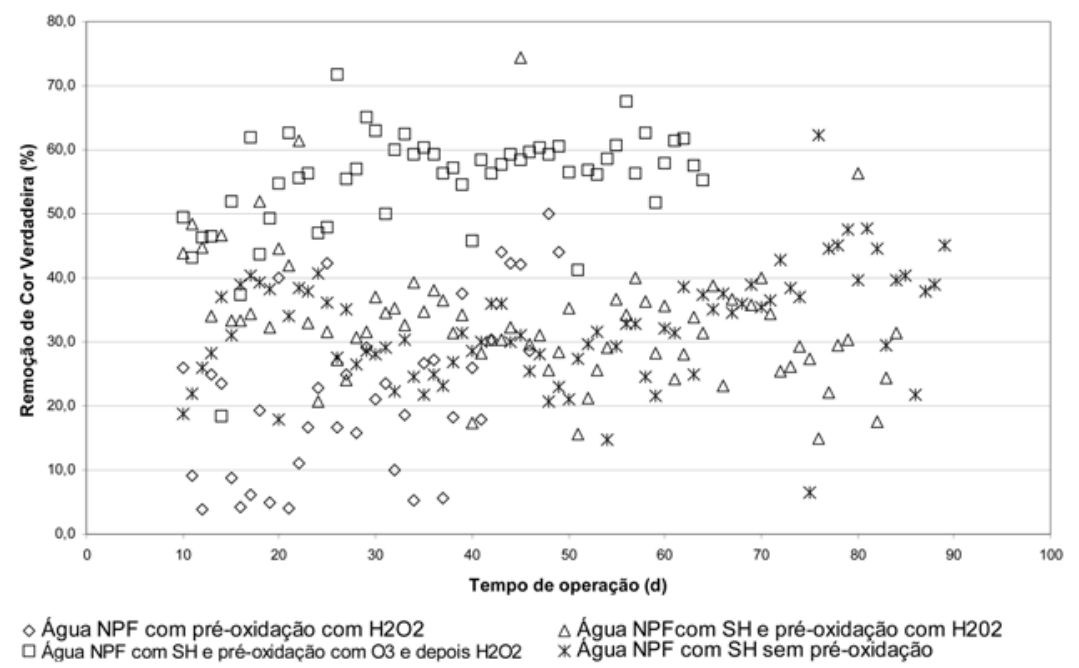

Figura 7 - Variações da remoção de cor no FLA2 em função do tipo de pré-oxidação (ozônio/peróxido ou peróxido/ozônio) com o tempo de operação nos ensaios 
camada biológica. Esse fato pode ser observado através da observação dos valores de remoção percentual de cor verdadeira obtida pelo FLA1, que caiu da faixa de 50 a $60 \%$ para a faixa de 30 a $40 \%$, conforme pode ser observado na Figura 10.

A Tabela 5 mostra um resumo dos resultados obtidos na remoção de cor verdadeira em função da pré-oxidação. Pode ser observado que quando foi utilizada água NPF sem pré-oxidação nos ensaios, os filtros lentos com leito de areia apresentaram remoção média de cor verdadeira de $33 \%$, enquanto os filtros com camada intermediária de carvão apresentaram remoção média de cor verdadeira de até 63\%. Para água NPF pré-oxidada, a remoção média nos processos oxidação/filtração com areia variou de 21,5 a 52,8\%, contra uma variação de 43,5 a $69 \%$ nos processos oxidação/filtração com carvão ativado. Quando foi utilizada água NPF/SH (água natural pré-filtrada com aplicação de substâncias húmicas) sem pré-oxidação nos ensaios, os filtros lentos com leito de areia apresentaram remoção média de cor verdadeira de $31 \%$, enquanto os filtros com camada intermediária de carvão apresentaram remoção média de cor verdadeira de 43,5\%. Para água NPF/SH préoxidada, a remoção média nos processos oxidação/filtração com areia variou de 33 a $46 \%$, contra uma varia-ção de 53,6 a $59,7 \%$ nos processos oxidação/filtração com carvão ativado.

\section{Remoção de absorvância}

Os filtros com camada intermediária de carvão ativado apresentaram resultados melhores de remoção de absorvância, com remoçôes percentuais médias de $56 \%$ contra $29 \%$ nos filtros de areia. A pré-oxidação com ozônio e depois peróxido apresentou resultados ligeiramente melhores de remoção de absorvância em água com aplicação de substâncias húmicas, como pode ser visto nas Figuras 11 e 12, obtida a partir dos dados do quinto ensaio.

\section{Remoção de coliformes totais}

Quanto à remoção de coliformes totais pode ser destacado que os pré-filtros removeram de 61 a $99 \%$ de coli- formes totais, conforme mostrado na Tabela 6. A remoção na coluna de ozonização foi de 99 a $100 \%$. A remoção devido ao peróxido, nas dosagens aplicadas, foi muito baixa, de 6 a $27 \%$. Nos filtros len-

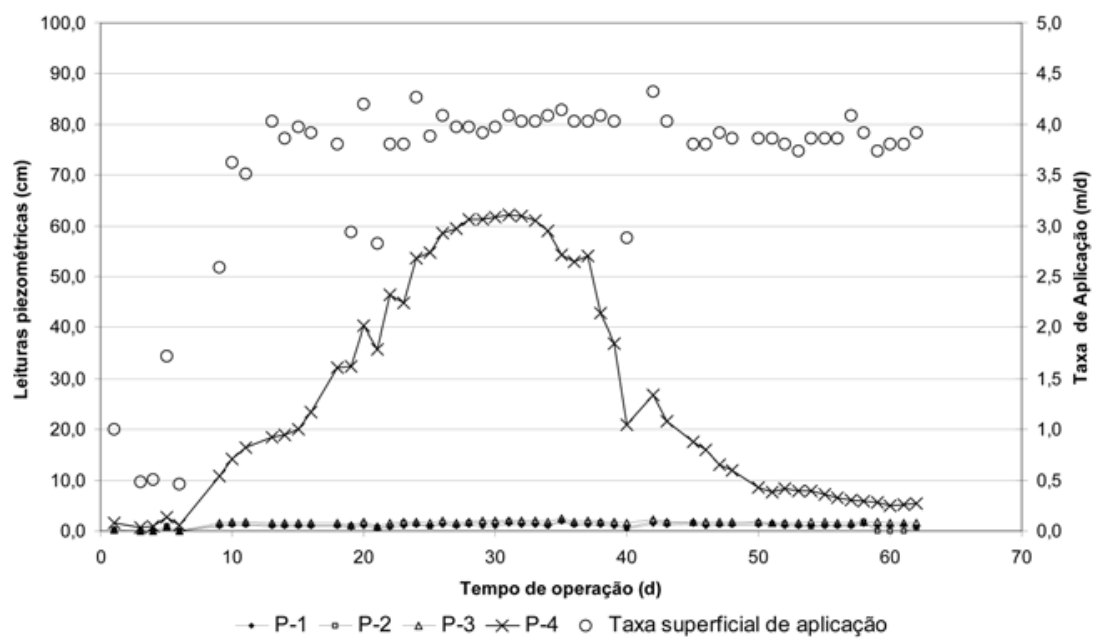

Figura 8 - Leituras piezométricas no filtro FLAI no segundo ensaio, sendo PI, P2, P3 e P4 pontos de leituras piezométricas ao longo do meio filtrante

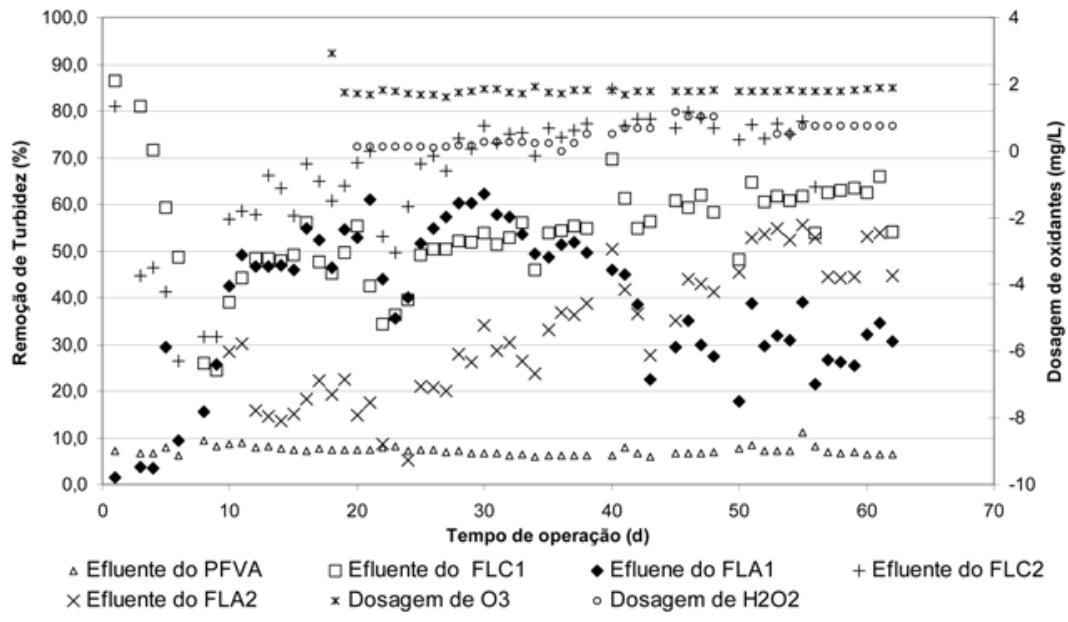

Figura 9 - Valores de remoção percentual de turbidez nos filtros lentos, turbidez afluente e dosagem de oxidantes no segundo ensaio

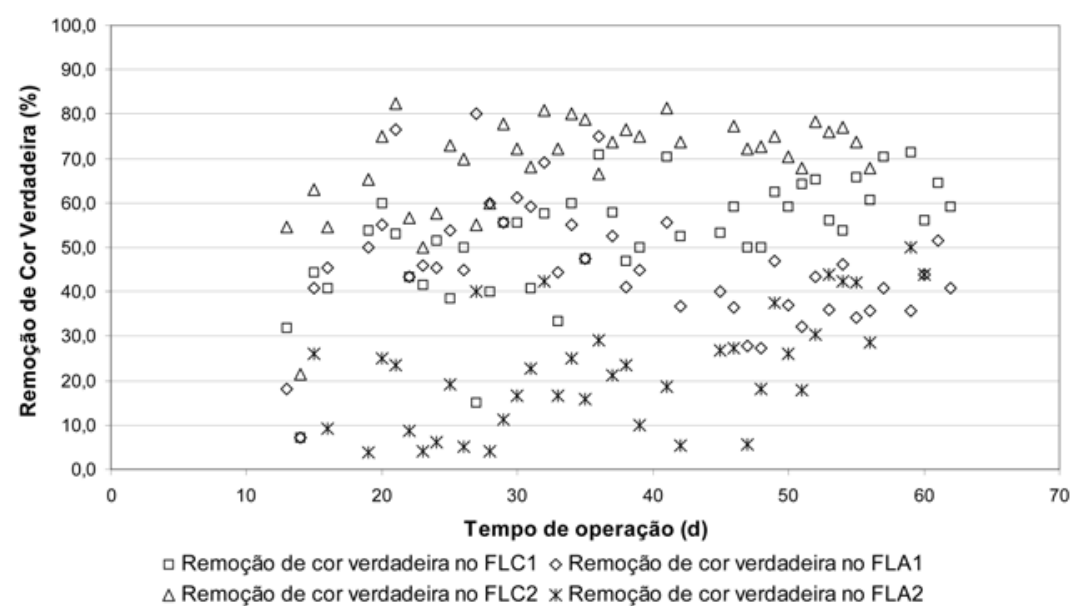

Figura 10 - Remoção percentual de cor verdadeira ocorrida nos filtros ao longo do tempo de operação no ensaio 2 
Tabela 5 - Remoção de cor verdadeira em função da pré-oxidação utilizada

\begin{tabular}{cccccc}
\hline Água utilizada & \multicolumn{4}{c}{$\begin{array}{c}\text { Remoção de cor verdadeira (\%) } \\
\end{array}$} & \multicolumn{2}{c}{ S/pré-oxidação } & \multicolumn{2}{c}{ C/oxidação } \\
& Areia & Areia+carvão & Areia & Areia+carvão \\
\hline NPF & 33,0 & 63,0 & 21,5 a 52,8 & 43,5 a 69,0 \\
NPF/SH & 31,0 & 43,5 & 33,0 a 46,0 & 53,6 a 59,7 \\
\hline
\end{tabular}

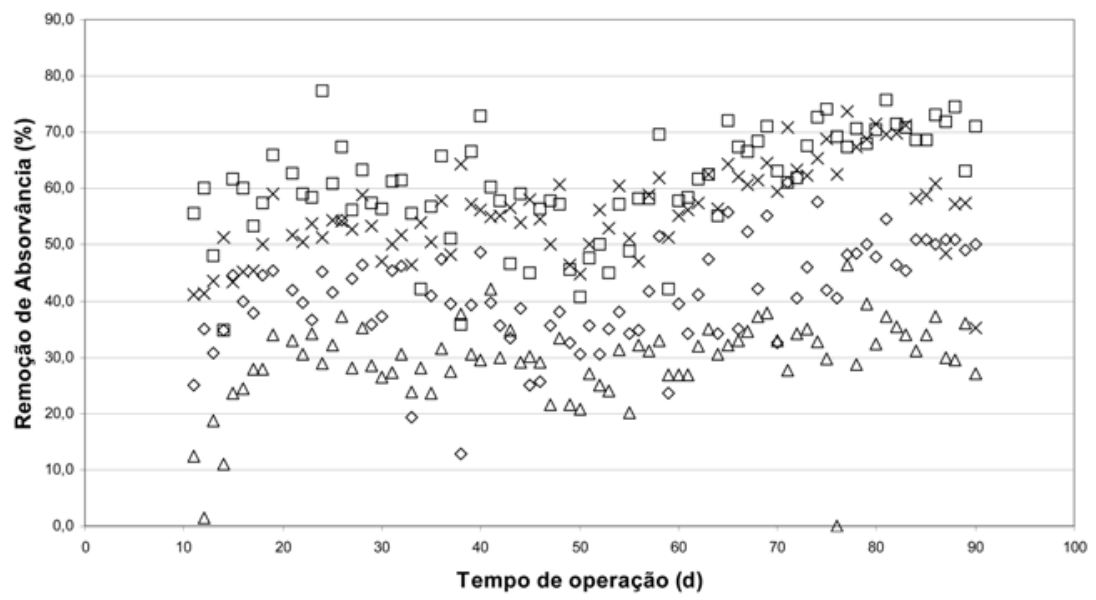

$\square$ Remoção no FLC1 $\diamond$ Remoção no FLA1 × Remoção no FLC2 $\triangle$ Remoção no FLA2

Figura I I - Remoção percentual de absorvância nos processos oxidação/filtração lenta ao longo do tempo de operação do quinto ensaio

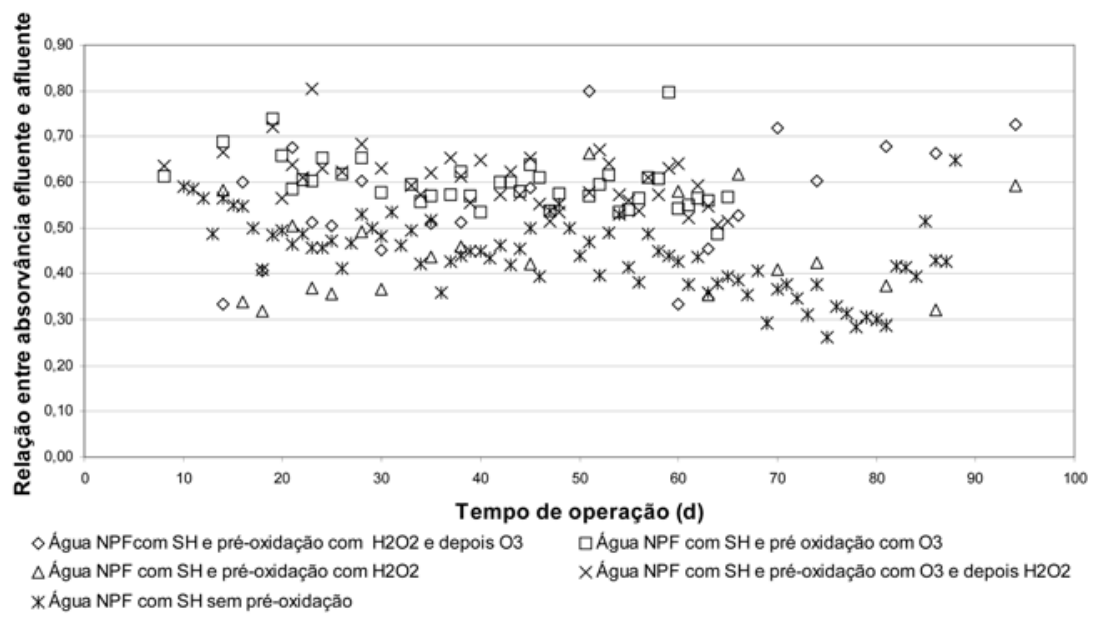

Figura I 2 - Relação entre valores de absorvância efluente e afluente dos filtros com CAG, nos ensaios com água NPF com aplicação de SH para cada tipo de pré-oxidação empregada

tos sem pré-oxidação a remoção variou de 81 a $100 \%$. Com pré-oxidação envolvendo o ozônio ocorreu ausência de coliformes, como era de se esperar. Mas com pré-oxidação com peróxido de hidrogênio a remoção variou de 42 a 98\%, indicando que o peróxido interfere na eficiência de remoção de coliformes nos filtros.

\section{Remoção de partículas}

A Figura 13 apresenta a distribuição média de partículas em cada ponto de amostragem, verificada no quinto ensaio. Nessa figura a sigla MF1-2 corresponde aos pontos de coleta à montante dos filtros FLC1 e FLA1 de água préoxidada com ozônio e depois peróxido de hidrogênio, a sigla MF3-4 corresponde aos pontos de coleta à montante dos filtros FLC2 e FLA2 de água com SH sem pré-oxidação e a sigla JC corresponde ao ponto de coleta na saída da coluna de ozonização. Pode ser observada a eficiência da pré-filtração bem como dos filtros lentos na remoção de partículas. É interessante observar o aumento no número de partículas de 2 micrômetros na coluna de ozonização, comparando os valores de jusante do PFVA com os da saída da coluna. Provavelmente a ozonização provocou a quebra das partículas maiores, com conseqüente aumento das partículas menores.

\section{CONCLUSÕES}

Com base no trabalho experimental realizado conclui-se:

- A qualidade da água bruta é de fundamental importância para o desempenho de uma instalação FiME, portanto é de fundamental importância a escolha do manancial a ser utilizado;

- Existe uma relação direta entre os parâmetros característicos da água bruta e do efluente da instalação FiME;

- A remoção de substâncias húmicas, medida através de parâmetros substitutivos como cor, absorvância e carbono orgânico dissolvido, é maior em filtros com camada intermediária de carvão ativado, precedido de pré-oxidação por ozônio ou ozônio seguido de peróxido de hidrogênio. Essa última combinação apresentou remoção média de $64 \%$ de cor verdadeira;

- O efeito do peróxido de hidrogênio não foi tão significativo quando aplicado sozinho ou mesmo quando aplicado antes do ozônio;

- Os residuais de peróxido de hidrogênio têm influência na camada biológica, com conseqüente interferência na remoção de turbidez e cor;

- A remoção de absorvância 254 nm, nos filtros com camada intermediária de carvão ativado e com pré-oxidação com ozônio e depois peróxido de hidrogênio obteve remoção na faixa de 40 a 60\%;

- A remoção de coliformes na coluna de ozonização foi de $100 \%$;

- O peróxido de hidrogênio apresentou remoção de 6 a $27 \%$ de coliformes totais, enquanto que os filtros lentos que receberam água pré-oxidada com peróxido de hidrogênio apresentaram remoções na faixa de 42 a $98 \%$, nas dosagens aplicadas; 
Tangerino, E. P. \& Di Bernardo, L.

Tabela 6 - Valores máximos e mínimos de remoção de coliformes totais nas unidades de pré-filtração, pré-oxidação e nos filtros lentos

\begin{tabular}{|c|c|c|c|c|c|c|}
\hline \multirow[t]{3}{*}{ Valores } & \multirow{3}{*}{$\begin{array}{l}\text { Pré-filtração } \\
\text { PFD+PFVA }\end{array}$} & \multicolumn{2}{|c|}{ Pré-odixação } & \multicolumn{3}{|c|}{$\mathrm{Na}$ filtração lenta } \\
\hline & & \multirow[t]{2}{*}{ Ozônio } & \multirow[t]{2}{*}{ Per. Hidr. } & \multirow[t]{2}{*}{ S/pré-oxid. } & \multicolumn{2}{|c|}{ C/pré-oxidação } \\
\hline & & & & & Ozônio & Per. Hidr. \\
\hline Máximos & 99 & 100 & 27 & 100 & 100 & 98 \\
\hline Mínimos & 61 & 99 & 6 & 81 & 100 & 42 \\
\hline
\end{tabular}

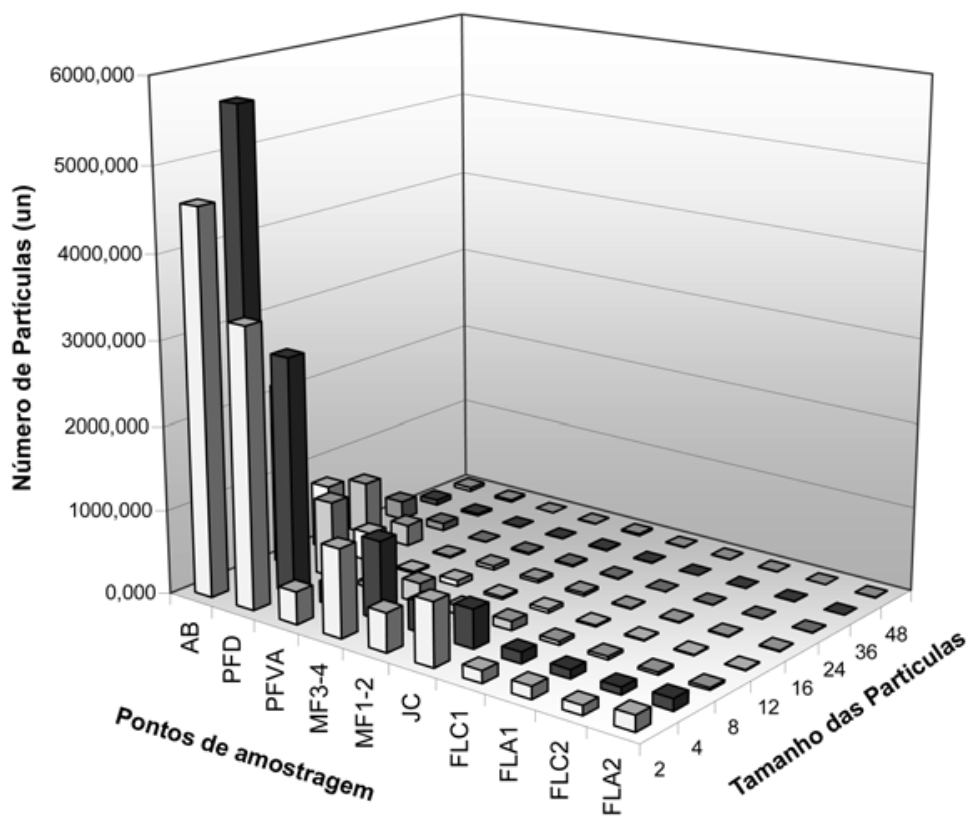

Figura I3 - Distribuição média de partículas em cada ponto de amostragem em função do tamanho das partículas, verificadas no quinto ensaio

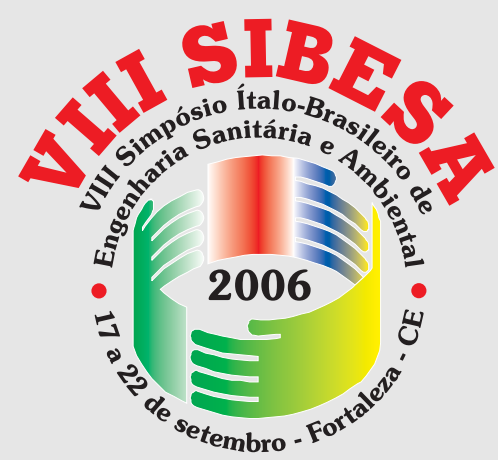

Recebimento de resumos 06/01/06

Comunicação aos autores 15/04/06

Envio de trabalhos completos 30/05/06

\section{REFERÊNCIAS}

COELHO, E. R. C. Influencia da pré-oxidação com ozônio e peróxido de hidrogênio na remoção de atrazina em filtros lentos de areia e carvão ativado granular. São Carlos. 248p. Tese (Doutorado) - Escola de Engenharia de São Carlos, USP. 2002.

DI BERNARDO, L. Métodos e técnicas de tratamento de água. ABES, RJ, 2 v. 1993.

FREESE, D.S. et al. Comparison of ozone and hydrogen peroxidelozone for the treatment of eutrophic water. Water Science Technology, v.39, n. $10-11$, p.325 a 328,1999 .

GALVIS, G.; LATORRE, J.; VISSCHER, J.T. Filtración en múltiples etapas, tecnologia innovativa para el tratamiento de agua. Versión Preliminar, Serie Documentos Técnicos. 89p. 1997

GRAHAM, N.J.D. Removal of humic substances by oxidation/biofiltration processes - a review. In: Selected Proceedings of the IAWQ-IWSA International Conference on Removal of Humic Substances from Water, Trondheim, Norway, p.141-148, June. 1999.

GREAVES, G.F.; GRUNDY, P.G.; TAYLOR, G.S. Ozonation and slow sand filtration for the treatment of coloured upland waters - pilot plant investigations. In: Slow Sand Filtration. Recent Development in Water Treatment Technology, Graham, N.J.D. ed. Ellis Horwood Limited. Great Britain, 153-162p. 1988.

LANGLAIS, B.; RECKHOW, D.A; BRINK, D.R. Ozone in water treatment. Application and engineering, Lewis Publishers, Inc. Chelsea, Micg. 569 p. 1991

YORDANOV, R.V.; et al. Biomass characteristics of slow sand filters receiving ozonated water. In: Advances in Slow Sand and Alternative Biological Filtration. GRAHAM N.L.D \& COLLINS R. ed. John Wiley \& Sons Ltd, England. p.107-118. 1996.

\section{Endereço para correspondência:}

\section{Edson Pereira Tangerino}

Departamewnto de Engenharia

Civil

Faculdade de Engenharia de llha

Solteira - UNESP

Alameda Bahia, 550

I5385-000 Ilha Solteira - SP -

Brasil

Tel.: (I8) 3743-I26I

E-mail:edtang@dec.feis.unesp.br 